\title{
Preservação da memória através da fotografia e sua disseminação para a comunidade universitária no âmbito da AGECOM/UFRN
}

\author{
Rafaela Karoline Galdêncio de Moura \\ Graduada em Biblioteconomia pela Universidade Federal do Rio Grande do Norte \\ E-mail: rafalalala22@gmail.com \\ Francisco de Assis Noberto Galdino de Araújo \\ Mestre em Ciência da Informação pela Universidade do Porto, Portugal \\ Professor do Departamento de Ciência da Informação da UFRN \\ E-mail: francisco_bibufrn@yahoo.com.br
}

\begin{abstract}
RESUMO:
Apresenta perspectivas relacionadas à preservação de fotografias impressas institucionais no âmbito universitário. Explicita o contexto da informação, caracterizando o documento enquanto suporte de representação da informação. Conceitua a memória para a promoção da comunicação, disseminação da informação e formas de estoque na mente humana. Enfoca a fotografia como meio de representação da informação documental ao qual assume papel fundamental na construção da memória; bem como os elementos constituintes que a tornam meio impresso ou digital. Aborda questões técnicas e reflexivas concernentes à preservação, conservação e disseminação da informação em coleções fotográficas. Esta pesquisa objetivou estudar as formas de acondicionamento e preservação das fotografias da Agência de Comunicação da Universidade Federal do Rio Grande do Norte, bem como perceber se existe divulgação destes materiais para a comunidade universitária. Finaliza o estudo com reflexões acerca da importância da preservação de fotografias para a construção da memória institucional enquanto um todo, com vistas a disseminação da informação ao público interno e externo frente à Universidade Federal do Rio Grande do Norte.
\end{abstract}

Palavras-chave: Memória institucional. Preservação de fotografias. Disseminação da informação. Agência de Comunicação.

\section{ABSTRACT:}

This article aims at presenting viewpoints related to the preservation of institutional pictures which had been printed in the university field. It explains both the context of the information, characterizing the document as a support of the information representation. It also conceptualizes the memory to the promotion of communication, to spread information and ways to keep it in the human mind. It emphasizes the photography as being a way of representation of documentary information which assumes a key role in the memory building - just as the elements which constitute it that makes it in either printed or digital format. It approaches technical and reflective issues about the preservation, conservation and dissemination of information in photographic collections. It has as a goal to study the ways of stowage and preservation of the pictures from the Communication agency of the Federal University of Rio Grande do Norte, and realizing the existence of divulgation of these materials to the college community. It finishes the study reflecting 
about the importance of keeping the pictures to the institutional memory building, aiming at spreading information to the internal and external public of the UFRN.

Keywords: Memory institutional. Preservation of Pictures. Dissemination of information. Communication agency.

\section{INTRODUÇÃO}

Desde a invenção da humanidade nos primórdios, a necessidade de existir uma memória documental sempre se fez presente na vida dos seres humanos, mais ainda nas organizações, com a finalidade de provar que algo aconteceu. No decorrer dos anos, com o avanço das tecnologias, a informação cresceu em quantidade e evoluiu principalmente nos seus formatos de representação e em caráter documental, fatores cruciais e significantes ao qual desperta a atenção da chamada sociedade da informação em se manter atualizado.

Diante da complexidade em trabalhar com objetos fotográficos, surgem curiosidades em realizar atividades específicas neste foco. Outro questionamento diz respeito se existe preservação e conservação de coleções iconográficas, e se estas são divulgadas para a comunidade universitária. Ao passo que as informações são produzidas constantemente, acredita-se que não existam práticas de preservação e conservação de coleções fotográficas devido à falta de conhecimento suficiente para estes fins, assim como é pensado que é inexistente a disponibilização destes materiais para a comunidade acadêmica, o que impede que o público universitário tenha conhecimento do acervo documental fotográfico.

Frente aos questionamentos supracitados, esta pesquisa objetivou estudar as formas de acondicionamento e preservação das fotografias da Agência de Comunicação da Universidade Federal do Rio Grande do Norte, bem como perceber se existe divulgação destes materiais para a comunidade universitária, haja vista que as fotografias funcionam como fonte de informação riquíssima para a instituição, com o fim de sugerir medidas preventivas de conservação das fotografias, bem como ampliar a disseminação destes materiais junto à comunidade da Universidade Federal do Rio Grande do Norte.

A fotografia é um recurso que permite provar as ações por meio das imagens. No entanto, com a evolução das fotografias impressas para o meio digital, muitas foram esquecidas em locais que comprometem sua estrutura. É crítico saber 
que em algumas instituições não possuem conhecimentos específicos no que concerne aos fatores de degradação das fotografias; entretanto, existem medidas que podem ser tomadas, evitando que tais materiais se percam com o tempo.

É neste contexto de fotografia como fonte de informação e resgate da memória institucional que o presente trabalho irá abordar os componentes que constitui a fotografia impressa, bem como irá apontar de que forma esse recurso pode ser melhor conservado e preservado, a fim de que no futuro pessoas do meio interno e externo à universidade tenham acesso a esses documentos, bem como a importância da disponibilidade destes documentos no âmbito acadêmico.

\section{INFORMAÇÃO, MEMÓRIA E PRESERVAÇÃO EM FOTOGRAFIAS}

Informação, palavra originária do latim informatio, de acordo com o Dicionário Aurélio significa "ato ou efeito de informar; notícia dada ou recebida; indagação". Ainda neste sentido, o DELTCI (Dicionário Eletrônico de Terminologia de Ciência da Informação), caracteriza como sendo um fenômeno social, que consiste em dar forma as ideias e emoções humanas, assim como a troca e interação dessas ideias e emoções (ato de comunicar). Tal significado trata-se de uma variação dupla de compreensão por se tratar de uma ciência multi e transdisciplinar.

Quanto as finalidades da informação, de acordo com o Oxford English Dictionary (1989 apud CAPURRO, 2007, p. 155), "visa moldar a mente e a comunicação do conhecimento". Neste sentido, Capurro (2007, p. 149), afirma que "o conceito de informação como usado no inglês cotidiano comunicado, desempenha um papel central na sociedade contemporânea". Desta forma, é permitido compreender que em qualquer lugar e tempo, a informação é primordial para o funcionamento de qualquer atividade, por mais simples ou complexa que seja. Outra finalidade é, decerto, a redução de incertezas em determinado contexto.

Capurro (2003 apud ARAÚJO, 2014, p. 70), ao estudar a evolução da ciência da informação, percebe que "algo é informacional na medida em que altera as estruturas de conhecimento do sujeito que se relaciona com dados ou documentos". A informação, é portanto, elemento fundamental para dar aos documentos o seu devido sentido, ao qual precisa ser tratada, organizada e disseminada na sociedade. 
Para adentrar a reflexão entre dados e documentos no contexto informacional, é possível apresentar alguns conceitos referentes ao campo da comunicação. A primeira delas diz respeito ao termo mentefato, que, de acordo com Silva (2006, p. 154) é o "produto da consciência, da mente, da razão e da inteligência humanas", ao qual entra em contrapartida com o termo artefato, caracterizado enquanto "produto tridimensional resultante do trabalho humano" (SILVA, 2006, p. 138). Este trabalho humano se relaciona intrinsicamente à produção de documentos ou livros na perspectiva da ciência da informação.

Nessa perspectiva, a comunicação é a estratégia que melhor se adequa a disseminação da informação, visto que o acesso à documentação se faz possível quando existe comunicação. Outra definição pertinente diz respeito a documentação, que em linhas gerais é o "conjunto de documentos" (SILVA, 2006, p. 146), ou seja, os documentos são reunidos, aos quais necessitam ser organizados, tratados e disseminados para que as informações nelas contidas não se percam futuramente.

Desde os primórdios, a memória sempre foi o fator de grande necessidade para a construção do saber histórico, visto que transcende os horizontes para "além da reconstrução histórica dos diferentes meios encontrados pelo homem para fixar, organizar e estabilizar" (LUCAS, 2000, p. 25), elementos primordiais para a memória.

Quanto ao conceito de memória, existem diversas abordagens devido ao sentido literário desta palavra. Segundo o dicionário Houaiss, alguns dos vários significados deste termo dizem respeito a "efeito da faculdade de lembrar, a própria lembrança; recordação que a posteridade guarda", características presentes nas atividades do ser humano. De uma forma geral, memória pode ser compreendida como "capacidade de reter e manipular informações adquiridas anteriormente" (SMIT; TÁLAMO, 2006, p. 2), ou seja, a cada informação recebida, a mente humana processará e guardará o que foi repassado.

Existe também a memória orgânica, que segundo o DELTCl1" "acumula e trata a memória pessoal e institucional”, ou seja, é observado que nas instituições, a produção de informação é constante, o que irá demandar grande volume de documentos; portanto, se faz necessário que tais informações sejam organizadas, tratadas e disseminadas.

Neste contexto, quando a evidência possui valor documental, as instituições de memória (arquivo, biblioteca e museu) surgem com o intuito de promover a

1 Documento on line, não datado, não paginado. 
preservação do patrimônio, seja histórico, cultural, científico, entre outros. O conceito de memória na perspectiva de Silva (2006), "engloba a pessoal e a institucional e consiste na capacidade de acumular informação em condições de uso fácil e rápido". Uma peculiaridade da memória diz respeito a seu caráter social, visto que "se trata de comunicação a outrem de uma informação, na ausência do acontecimento ou do objeto que constitui o seu motivo" (FLORÈS, 1972, p. 12 apud LE GOFF, 2013, p. 389), assim como ela "faz parte [...] do imaginário partilhado entre indivíduos e coletivos que na dinâmica do tempo produz, enuncia e significa o que chamaremos de informação" (PIMENTA, 2013, p. 151-152). Desta forma, a memória quando partilhada é o meio fundamental para que a construção da história na sociedade seja promovida e divulgada a quem desejar recuperar a informação quando for preciso.

No âmbito da ciência da informação, os acontecimentos de qualquer contexto ficam marcados em diversos segmentos, dentre elas o institucional, que abarca uma infinidade de coleções documentais. Assim como a informação é o conjunto de dados processados, a memória é:

[...] algo que vai muito além do próprio conteúdo do documento. Os conjuntos informacionais que se geram não podem ser definidos compartimentadamente como material de arquivo, de biblioteca ou de centro de documentação, por serem atípicos, como totalidade, a qualquer um deles. Esses conjuntos de dados constituem a memória (BELLOTTO, 2005, p. 271).

Neste ínterim, os materiais de arquivo, biblioteca ou de centro de documentação fazem parte da memória, visto que os documentos possuem o caráter de evidenciar determinado acontecimento. A memória também é compreendida como uma espécie de conhecimento materializada, visto que agrupa uma série de informações em diversos suportes. Sendo assim, "a memória, tanto individual como coletiva, atua na construção do conhecimento. [...] sem memória não somos capazes de reconhecer determinada informação" (PIMENTA, 2013, p. 155).

No entanto, surge um questionamento no tocante ao acesso. Segundo Pimenta (2013, p. 155) "é igualmente correto dizer que sem o acesso à informação, seja ela qual for para determinado fim, torna-se impraticável a produção e preservação da memória”. Como acessar uma informação que não está disponível? De acordo com Ribeiro (2003, p. 569) "Desde 1887 até aos nossos dias, a preocupação em criar meios de acesso à informação dos arquivos tem tido uma expressão cada vez mais acentuada". 
Assim como a memória tem seus elementos, compostos pelos documentos, a arquivologia viria para resolver os problemas no que tange a organização destes. Desta forma, entende-se que as informações sejam geradas, preservadas, conservadas e disponibilizadas para a comunidade. Desta forma, para Silva (2006, p. 137), a arquivologia caracteriza uma abordagem científica sobre arquivo, enquanto espaço institucional ou funcional.

A organização da memória só é possível após o acontecimento dos fatos como afirma Bellotto (2005, p. 272-273), em que se reúnem as informações de determinado evento, gerando os documentos, e após isso, a captação do corpus documental, que "é matéria documental em estado bruto", corpus este que significa a memória.

Assim, o termo documento, derivado do latim docere, que significa ensinar, passa a ter significado de prova com a finalidade de justificar algo real. Quanto ao seu conceito, segundo Bellotto (2006, p. 35) "documento é qualquer elemento gráfico, iconográfico, plástico ou fônico pelo qual o homem se expressa”. Silva (2006, p. 145) caracteriza documento como sendo "informação registrada num suporte humano e material/tecnológico", ou seja, é o meio pela qual as informações nela contidas irão servir como fonte de referência ou como elemento de prova referente a alguma evidência.

Em se tratando de memória institucional, de forma geral, pode ser entendida como o conjunto de informações reunidas dentro de uma instituição. E dentro de uma organização, é comum que haja um agrupamento de documentos, denominados arquivos. São características vitais da memória institucional: recolher, tratar, transferir e disseminar as informações contidas em cada material, independente do seu suporte. O conceito formal de memória é definido como

[...] conjunto de informações e/ou documentos, orgânicos ou não. A memória é referenciadora, e não recolhedora ou armazenadora. Os documentos existem nos seus lugares, sem que se tente reuni-los materialmente. Basta que a informação esteja captada, o objeto identificado, localizado e disponível para o pesquisador (BELLOTTO, 2005, p. 274).

É importante ressaltar que não se devem confundir os conceitos e as características da memória, pois se ela é referenciadora, isso significa que o conteúdo informacional presente nos documentos servirá como fonte de informação para provar que algo aconteceu, ou seja, as informações serão recolhidas; tratadas porque se o documento corre o risco de sofrer degradação, existe a necessidade de 
evitar que as informações se percam com o tempo; transferidas e disseminadas ao público para que a sociedade tenha ciência do que houve na história, tendo em vista a abertura e ampliação do conhecimento, o que possibilita o diálogo entre as pessoas.

Sendo assim, os conjuntos de informações formam os documentos, independente qual seja o suporte, assim como conjuntos de documentos são agrupados nas instituições de memória (arquivos, bibliotecas ou centros de documentação); as instituições de memória, além de promover a preservação do patrimônio, são responsáveis pelo ajuntamento e tratamento de informações aos documentos, tornando um corpus documental significativo, bem como são responsáveis pela organização e disseminação da informação na sociedade quando for preciso.

É sabido que desde os primórdios, o homem busca representar suas emoções e vivências através da arte, ao qual foram iniciadas com as pinturas em cavernas. Segundo Marcondes (2005, p. 2), "o uso da imagem como forma de registro remonta à época do homem das cavernas. Cenas de lutas, de guerras e do cotidiano eram pintadas em cavernas e paredes, tornando possível, atualmente, a compreensão de culturas passadas." Imagem, que para Silva (2006, p. 149) é, portanto, a "representação mental e afectiva de natureza icónica, (re)produzida naturalmente pelos seres humanos e por estes através de tecnologia". De modo geral, a mente humana é capaz através de dar forma aos seus pensamentos por meio da iconografia, objeto da arte.

Kossoy (2001, p. 37) explicita que "três elementos são essenciais para a realização de uma fotografia: o assunto, o fotógrafo e a tecnologia". Para o autor, entende-se que a fotografia é o resultado da ação humana que registrou algo em determinado tempo por intermédio do aparato tecnológico. Neste ínterim, a fotografia se caracteriza como fonte de informação e objeto de arte, ao qual possui um conceito bastante sublime. Para Achutti (2004, apud EGGERT-STEINDEL et al., 2013, p. 130) as fotografias "são o resultado de um só gesto, um gesto último e definitivo, aquele de apertar o disparador".

Outra finalidade peculiar da fotografia diz respeito a seu valor documental. Segundo Marcondes (2005, p. 2) “a imagem fotográfica atesta apenas aquilo que é mostrado, ou seja, não permite conotações por tratar-se de uma mensagem sem código...logo, o seu valor como documento e a importância de sua presença nos 
arquivos é atualmente inquestionável”. Assim como para cada documento existem fatores que marcam o contexto informacional, com a fotografia não é diferente, pois "tanto imagem quanto memória podem se referir a diferentes áreas ou processos [...] e é ela que alimenta a construção de outras imagens" (LEITE, 1998, p. 10). Logo, a construção de várias imagens confere ao "desencadeamento de lembranças de fatos passados, já adormecidos", ao qual "Ihe conferem papel fundamental na reconstrução histórica" (MARCONDES, 2005, p. 1), característica fundamental presente no uso de fotografias, ao fazer reflexões no que concerne à preservação da memória documental.

Fotografias mostram pessoas, lugares e eventos; citações e fontes são verificadas. Em cada caso é razoável vislumbrar a "informação-como-coisa" como evidência, embora sem implicar que o que foi lido, visto, ouvido ou percebido ou observado tenha sido necessariamente exato, útil ou pertinente aos propósitos do usuário (BUCKLAND, 1991, p. 353).

Há quem diga que a fotografia impressa é uma imagem fixa em um papel, no entanto, "com o desenvolvimento da indústria gráfica, que possibilitou a multiplicação da imagem fotográfica em quantidades cada vez maiores através da via impressa, iniciou-se um novo processo de conhecimento do mundo, porém de um mundo em detalhe" (KOSSOY, 2001, p. 26), então, se existem detalhes, este fator diz respeito que a fotografia tem a sua estrutura; desta forma, existem materiais que a compõem, dividida em três camadas, aos quais são: suporte primário - metal, placas de cobre, vidro ou papel, que são a base estrutural da imagem -, camada aglutinante (ou formadora da imagem) - albúmen, colódio e gelatina, materiais responsáveis pela cor da fotografia - e o material formador da imagem final - formados por "prata metálica, platina e uma ampla variedade de corantes e pigmentos" (KENNEDY; MUSTARDO, 2004, p. 19), estes são responsáveis pela visibilidade da imagem.

Com a evolução dos suportes, o homem sentiu o "desejo de registrar com maior realismo que levou ao aparecimento nos séculos XVI e XVII de máquinas de desenhar e retratar" (MARCONDES, 2005, p. 2), assim como as primeiras máquinas fotográficas começaram a surgir, fator este que possibilitou ao homem a descobrir os métodos de captação de imagens em tempo real, dentre elas, a fotografia digital, que revolucionou a forma de captura de imagem desde o surgimento dos filmes em bases flexíveis, como também a praticidade em poder visualizar aquilo que foi 
capturado, se foi de boa qualidade, se necessita repetir a ação de fotografar, entre outros fatores.

Segundo Trigo (1998, p. 166) "o que dá vida a uma imagem digital é a quantidade de pixels (picture elements)." Essas quantidades de pixels são representadas por softwares específicos de linguagens de programação em computadores, que consistem na transferência de códigos (formados por letras e símbolos) quando o arquivo digital é processado através de escaneamento (para digitalização de fotos impressas) ou no "descarregamento" de fotografias das câmeras digitais.

A memória institucional contém uma infinidade de coleções documentais, no entanto, todo material físico, no momento que é produzido, inicia-se a um processo de deterioração impossível de ser interrompido, podendo-se apenas retardá-lo (MARCONDES, 2005, p. 8). Nesta perspectiva, a utilização de pequenas medidas possibilita ao material maior durabilidade, ou seja, existem estratégias que irão fazer diferença ao "tempo de vida" documental, chamadas de preservação e conservação, a fim de que evitem a agressão do material.

É de extrema relevância que, no contexto geral da informação se tenha ciência dos conceitos "preservar" e "conservar". Segundo o DELTCl2 ${ }^{2}$, preservação é o "conjunto de medidas de gestão tendentes a neutralizar potenciais factores de degradação de documentos", ou seja, esta medida parte exclusivamente de uma ação humana para que a memória seja perpetuada. Seguindo este princípio, a conservação:

É um conjunto de medidas e estratégias administrativas, políticas e operacionais que contribuem direta ou indiretamente para a conservação da integridade dos acervos e dos prédios que os abrigam. São ações para adequar o meio ambiente, os modos de acondicionamento e de acesso, visando prevenir e retardar a degradação (SPINELLI, 2011, p. 4).

Destarte, para que esse conceito seja aplicado aos documentos do patrimônio institucional, é primordial que os conhecimentos específicos referentes a preservação e conservação sejam transferidos para as pessoas que fazem o ambiente de trabalho, a partir da iniciativa de que cada um pode fazer a sua parte planejando estrategicamente ações operativas, refletindo em ações mais humanitárias na sociedade. Vale lembrar que, embora a preservação pareça ser

2 Documento on line, não datado, não paginado. 
uma ação tão simples, torna-se, ao mesmo tempo, algo essencial, cujas próximas gerações agradecerão pelo fato de existirem documentos, pois como ressalva Bellotto (2005, p. 300), "preservam-se documentos por sua capacidade de servir como prova (evidential value) ou como testemunho (information value)".

No tocante a conservação, este se caracteriza este termo como conjunto de diretrizes operativas para o manejo e utilização sustentada de recursos, a um nível ótimo de rendimento e preservação. Dessa forma, para que as coleções da memória possam estar acessíveis, se faz necessário ações de conservação, medidas simples, porém significativas, como ressalta Teixeira:

O estado de conservação de um objeto está intrinsecamente ligado ao
material no qual foi elaborado, na técnica construtiva e na trajetória das
condições de armazenagem e exposição. Quando um objeto é mantido em
condições adequadas na armazenagem e exposição, os fatores de
degradação são estabilizados, necessitando apenas a sua manutenção com
procedimentos preventivos de conservação (TEIXEIRA, 2012, p. 15).

Nesta perspectiva, é comum que no âmbito da ciência da informação e em coleções institucionais existam dificuldades na preservação de fotografias, por haver

[...] desconhecimento sobre a constituição desse tipo de material. Em outras palavras, trata-se de um tipo de documento ainda bastante desconhecido, do ponto de vista de sua constituição material, na maioria das instituições. Portanto, o desejo em perpetuar as imagens fotográficas nem sempre resulta em preservação do documento, sobretudo se não houver uma política voltada à preservação com recursos destinados especificamente a esse fim (MARCONDES, 2005, p. 2).

Sabe-se que as fotografias impressas possuem um "tempo de vida", por se tratar de um recurso que contém substâncias que podem se degradar com o tempo. Costa (2009, p. 25) define deterioração como sendo "o nome dado a toda e qualquer modificação química ou física que ocorrem nos objetos. No âmbito das espécies fotográficas, se entendem como deterioração as transformações, posteriores ao processamento". Desta forma, existem diversos fatores que comprometem a estrutura das fotografias, no que concerne ao local e materiais de armazenamento, manuseio, agentes biológicos e fatores intrínsecos.

Quanto às estratégias de preservação de fotografias, na literatura há uma presença razoável referente a esse tema. Em se tratando de uso de componentes que evitasse a degradação, uma delas foi o uso do colódio, um dos componentes que constituem as fotografias impressas. 
No tocante ao acondicionamento, existem algumas medidas que podem ser utilizadas nas instituições de memória. Inicialmente, é fundamental que se faça um diagnóstico organizacional, pois é através dele que "identificam-se os materiais e processos fotográficos que compõem o acervo" (CUNHA; PEREZ, 2014, p. 50). Segundo Baruki e Coury $(2004$, p. 1) "o diagnóstico de um acervo fotográfico é realizado através de um levantamento do estado de conservação dos documentos, enumerando-se as características de deterioração nele encontradas". Após isso, são apontadas as melhorias necessárias para a prática da preservação, ao qual visa a redução de gastos com problemas que poderão ocorrer futuramente com 0 documento, de forma que o objeto (neste caso, a fotografia) permaneça em seu estado inicial.

Todavia, por se tratar de um processo multidisciplinar, é passível que haja uma gama de saberes diferentes, mas é possível a realização de tais atividades. Para tanto, se faz necessário a presença de especialistas em fotografia, que conhece a fundo os componentes químicos da mesma, o profissional da informação para desempenhar as atividades relacionadas à gestão e organização dos documentos e uma equipe de suporte. Importante ressaltar que

A conservação deve ser mais que uma medida adotada isoladamente, deve
ser uma atitude, da qual todos os funcionários do arquivo, e não apenas o
conservador, devem ter consciência. A manipulação correta e o respeito
pelo documento devem estar presentes nas atitudes de toda equipe, pois
esse ato certamente irá garantir uma maior longevidade ao documento
(MARCONDES, 2005, p. 9).

A preservação de fotografias digitais pode ser considerada uma alternativa de preservação da memória institucional que consiste na obtenção de cópias de segurança (MARCONDES, 2005, p. 6).

É importante ressaltar que a informação enquanto meio (independente do suporte disponível), assume uma variedade de pensamentos e significados no foco científico; ao mesmo tempo, é o elemento fundamental para o funcionamento da comunicação na sociedade, mais ainda no meio institucional, que possibilita a construção do saber em várias áreas. Não obstante, o documento surge com essa ideia, assim como possibilitar a associação do conhecimento na mente humana por meio das imagens, fundamentais para o compartilhamento das informações a outras pessoas, tornando a memória individual para o meio coletivo, no intuito de promover a construção do saber histórico a diversas gerações; nesse ínterim, a fotografia 
enquanto fonte de informação se faz presente como instrumento de prova (ou valor documental) referente a determinado acontecimento; porém, é necessário que ações preventivas e estratégicas sejam tomadas para que a memória seja disseminada e durável por longos tempos a fim de que as gerações futuras percebam que a história institucional carrega uma infinidade de informações valiosas, pois é melhor preservar do que restaurar.

\section{PRESERVAÇÃO DA MEMÓRIA ATRAVÉS DA FOTOGRAFIA E SUA DISSEMINAÇÃO PARA A COMUNIDADE UNIVERSITÁRIA NO ÂMBITO DA AGECOM/UFRN}

A Agência de Comunicação (AGECOM) tem como principal finalidade comunicar as atividades e eventos institucionais da Universidade Federal do Rio Grande do Norte. Responsável pela produção e disseminação da informação na sociedade, a AGECOM objetiva informar a comunidade questões relacionadas à diversidade do conhecimento, construção de novos saberes, inovação, tecnologia e atividades realizadas no âmbito da UFRN, ao qual é dividido em três plataformas: ensino, pesquisa e extensão. Criada em 1999, era chamada por Assessoria de Imprensa, que passou a integrar a Superintendência de Comunicação (COMUNICA) assim como a TV Universitária (TVU) e a Universitária FM $(88,9)$ também fazem parte deste conjunto. Convém ressaltar que a AGECOM é subordinada à Reitoria, localizada no Campus Central da UFRN.

Desde o momento em que a AGECOM foi incorporada à antiga Assessoria de Imprensa da UFRN, o acervo fotográfico passou a ser estruturado, considerado uma "herança" em que a Assessoria possuía, visto que sempre acontecia eventos no âmbito universitário. Desde então, a AGECOM tenta aprimorar as formas de construção e de preservação desse acervo de acordo com o surgimento das novas tecnologias. No entanto, são poucas as pessoas que têm conhecimento desta coleção memorável de fotografias.

No tocante ao conteúdo informacional das fotografias, é possível observar em grande escala os seguintes detalhes: presença de pessoas referenciais, como Reitores, Professores, Ministros, entre outros; bem como eventos de grande porte, como a criação da Maternidade Leide Morais; do Departamento de Odontologia e demais unidades no interior, as edições da CIENTEC e 2 edições da SBPC; é 
perceptível também nas fotografias informações referentes à criação do Campus Universitário desde a construção. Sob este olhar, o acervo fotográfico é referência para todos os setores da Instituição, como também no sentido externo.

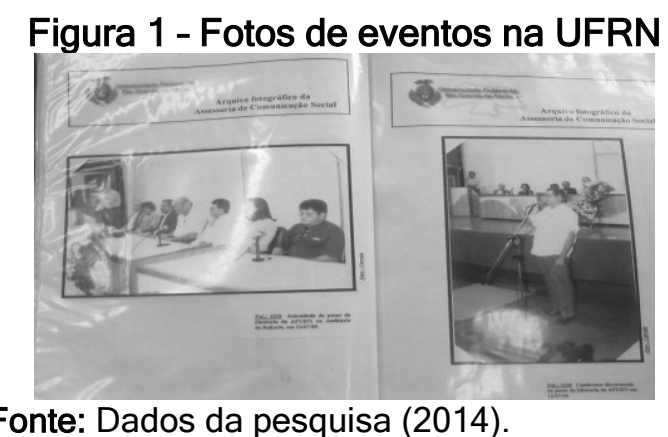

Em contrapartida, ao se tratar dos métodos de preservação e conservação dos materiais, não existe processo de higienização para o arquivamento das fotografias impressas, ao qual estas recebem um tratamento paliativo, bem como a conservação e preservação destes materiais não são notados. Também é inexistente a periodicidade de limpeza do acervo, fatores estes que, para a responsável (em exercício durante o momento da pesquisa) não são considerados enquanto trabalho adequado. Sob este entendimento, a instituição sente a necessidade de um profissional da área de Biblioteconomia, Arquivologia ou Museologia, sem saber ao certo qual será a área mais competente para as funções de recuperação da informação e conservação das fotografias dentro dos padrões. Em linhas gerais, o acervo fotográfico está sendo trabalhado através de bolsista na área de Biblioteconomia, ao qual atua no período da manhã.

No que tange ao armazenamento das fotografias impressas da AGECOM, durante a pesquisa de campo foram observados alguns aspectos no tocante as formas de acondicionamento. Parte do material fica armazenado dentro de sacos plásticos guardados em pastas arquivos, outras em pastas plásticas e grande parte ficam misturadas, sem identificações de assunto ou período, soltas em sacos plásticos. As fotos estão em processo de digitalização, mas não existe nenhum processo de higienização antes da armazenagem nem antes da digitalização. As fotos armazenadas nas pastas plásticas são fixadas no papel sulfite através de Rev. Inf. na Soc. Contemp., Natal, RN, v.1, n.3, jul/dez., 2017 | 
pequenos cortes onde são introduzidas as pontas da imagem, sendo dispensável a colagem.

Figura 2 - Disposição armário aberto

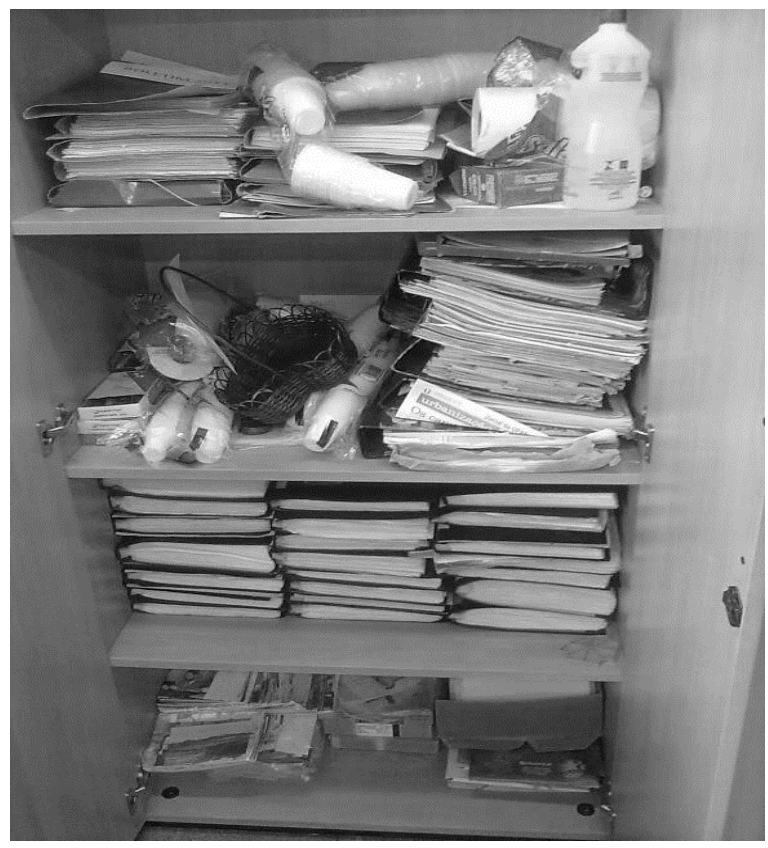

Fonte: Dados da pesquisa (2014).

As pastas plásticas, apesar de serem dispostas no sentido horizontal, não possuem bibliocantos e o seu empilhamento dificulta a retirada de uma delas acarretando, dessa forma, o desabamento de todas. Também devido ao seu acondicionado em um armário, não possui iluminação nem ventilação. O armário do acervo fotográfico impresso fica próximo a uma janela envidraçada sem proteção contra a radiação ultravioleta, ocasionando assim, uma temperatura oscilante provocada pelo abrir e fechar do armário.

Quanto à preservação e conservação da memória imagética na AGECOM, é inexistente a presença de fungos e mofos, assim como também não há insetos apesar de não existir uma limpeza interna no armário.

No tocante a disseminação do acervo fotográfico, a comunidade universitária (docentes, alunos e funcionários) pode ter acesso ao material para consulta. Todavia, não existe um controle adequado para esse tipo de serviço, assim como o profissional responsável para este trabalho é técnico-administrativo sem conhecimento específico. É válido ressaltar que durante a realização da pesquisa, foi detectado a falta de comunicação entre os funcionários quando se trata do acervo 
fotográfico impresso, tanto na preservação e conservação, bem como na divulgação desse material; assim como não é discutido com frequência algum tipo de estratégia para melhoria na preservação da informação das imagens. No entanto, é válido considerar que as fotografias são um patrimônio documental de grande valia. Existe a perspectiva de disponibilizar o acervo para a comunidade não só para a comunidade universitária, mas também para o público externo apenas para fins de consulta. Quanto ao acervo fotográfico digital, existe a disseminação de algumas fotografias acompanhadas de matérias criadas na AGECOM. Uma delas está presente no Portal da UFRN, conforme figura a seguir.

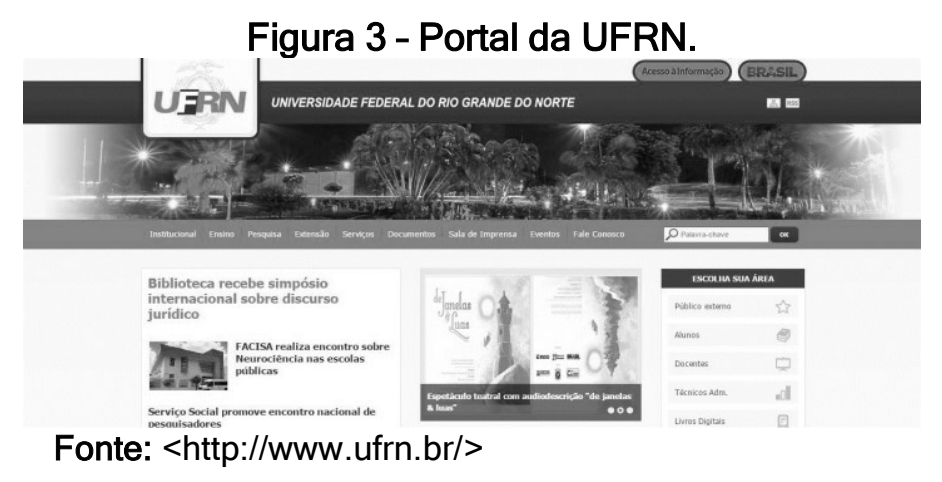

Diante da necessidade de melhorar os aspectos de preservação e conservação em fotografias, seguem algumas medidas preventivas que possibilitem a duração dos materiais, com base em estudos aplicados segundo Pozzebon (2013, p. 13), compostos de atitudes preventivas.

$\checkmark \quad$ Evitar colocar um grande número e diferentes formatos de fotografias em pastas, envelopes ou caixas;

$\checkmark \quad$ Fixar as estantes metálicas, evitando o tombamento e o efeito dominó; $\checkmark$ Guardar as fotografias acondicionadas em envelopes de material neutro e armazenadas dentro de caixas, estas que por sua vez, deverão estar dentro de armários de aço;

Evitar a utilização de pastas suspensas em arquivos de aço, pois as fotografias podem deslocar-se e ficarem prensadas entre as pastas e as hastes de sustentação;

$\checkmark \quad$ Não aplainar ou empilhar fotografias enroladas;

$\checkmark \quad$ Utilizar armários de aço, evitando assim oscilações de temperatura e UR (Umidade Relativa) e o contato com o pó. 
Outro fator significante para o tratamento dessas coleções diz respeito ao profissional competente para lidar com tais materiais, haja vista que por se tratar de um suporte informacional específico, este necessita de cuidados diferenciados para que a memória institucional não se perca. Durante a realização da pesquisa, um fato que chamou a atenção foi o pensamento da vice-gestora (em exercício) frente a essa necessidade, que é a realização de um trabalho através de parceria com profissionais no âmbito da UFRN que possuam as competências para executar as atividades propostas, possibilitando que a digitalização das fotografias impressas seja continuada e demais atividades possam ser desenvolvidas.

Quanto à disseminação das coleções fotográficas, é proposto que seja criado e divulgado um acervo fotográfico em site institucional ou sistema, ambas tecnologias em rede, assim como as informações jornalísticas são disseminadas; ao qual este trabalho pode ser desenvolvido através das parcerias entre os setores na UFRN, a fim de que a recuperação da memória seja promovida e a informação esteja acessível para a comunidade universitária e aos usuários externos.

\section{CONSIDERAÇÕES FINAIS}

A informação com os seus conceitos e finalidades é apresentada em diversos meios e suportes, o que não deixa de ter os objetivos principais: dar aos documentos o seu devido sentido e proporcionar ao homem a redução de incertezas em determinado contexto, fatores estes em que a informação precisa ser tratada, organizada e disseminada na sociedade, haja vista que no mundo atual a comunicação é constante e diversificada em seus meios. Uma forma que possibilita a interação humana na sociedade é a descoberta da informação em documentos, que traz dentro de si uma gama de saberes referentes a algum acontecimento, servindo de evidência para as próximas gerações.

Neste sentido, a memória se faz necessária para a construção do saber humano, principalmente no fator histórico, a partir do momento em que o conhecimento registrado na mente humana passa do nível individual para o meio coletivo, resultando em ações que possibilitem a construção da memória coletiva, dentre elas, a criação das instituições de memória, que organizam, tratam e disseminam informação para a sociedade, no intuito de tornar possível a materialização do conhecimento humano e a transferência da informação a todos os 
segmentos da sociedade, dentre elas, o institucional, ao conter fontes que registram uma série de acontecimentos.

Portanto, a fotografia como fonte de informação é considerada um meio de expressão das artes, das emoções humanas, assim como o registro de acontecimentos em certo tempo. Caracterizado como elemento que facilita o processamento das ideias e conhecimentos na mente humana, é notável que este suporte passou por diversas transformações, com o surgimento e evolução das tecnologias, no intuito de ser aperfeiçoado e melhor trabalhado. No contexto institucional, a fotografia registra informações de grande valia na construção do patrimônio documental, fatos memoráveis e demais fatores significantes no meio local.

Diante deste contexto, para que a memória seja perpetuada, algumas ações são fundamentais, neste caso em específico, a importância da preservação e conservação de materiais fotográficos, a fim de que a degradação desses materiais seja retardada. Em contrapartida, por se tratar de métodos específicos, é normal que em instituições públicas existam dificuldades para a promoção de tais atividades, porém não deixa de ser possível, visto que no âmbito universitário a interdisciplinaridade se faz presente. Contudo, ao se tratar do acesso à informação em coleções fotográficas institucionais, tais coleções nem sempre são divulgadas, o que traz preocupações quando existe a necessidade por parte de alguém, assim como este não tenha conhecimento de que o acervo fotográfico existe.

Frente a essa realidade, os objetivos da pesquisa concernente aos materiais iconográficos da AGECOM foram alcançados, ao qual necessita de um trabalho árduo e intenso referente ao estabelecimento de parcerias entre as áreas de Biblioteconomia, Arquivologia e Comunicação para o tratamento adequado nas coleções fotográficas, assim como promover a disseminação da informação no âmbito universitário, a fim de que a memória seja eternizada em seus suportes, meios de comunicação e disseminada ao público sem restrições. 


\section{REFERÊNCIAS}

ARAÚJO, Carlos Alberto Ávila de. Fundamentos da ciência da informação: correntes teóricas e o conceito da ciência da informação. Perspectivas em Gestão \& Conhecimento, João Pessoa, v.4, n.1, p.57-79, Jan./Jun. 2014. Disponível em: $<$ http://periodicos.ufpb.br/ojs/index.php/pgc/article/view/19120/10827>. Acesso em: 15 Set. 2014.

BARUKI, Sandra; COURY, Nazareth. Treinamento em conservação fotográfica: a orientação do Centro de Conservação e Preservação Fotográfica da Funarte. In: Cadernos técnicos de conservação fotográfica (Organização do Centro de Conservação e Preservação Fotográfica da Funarte). Rio de Janeiro: Funarte, 2004, v. 1, p. 1-7. Disponível em:

<http://www.funarte.gov.br/preservacaofotografica/wpcontent/uploads/2010/11/cad1_ port.pdfcontent/uploads/2010/11/cad1_port.pdf>. Acesso em: 11 Out. 2013.

BELLOTTO, Heloísa Liberalli. Arquivos permanentes: tratamento documental. 3. ed. Rio de Janeiro: FGV, 2005. 318 p.

BUCKLAND, Michael K. Information as thing. Journal of the American Society for Information Science, v. 42, n. 5, p. 351-360, 1991. Disponível em:

<http://skat.ihmc.us/rid=1KR7VC4CQSLX5RG5T39/BUCKLAND\%281991\%29inform ationasthing.pdf>. Acesso em: 15 Ago. 2014.

CAPURRO, Rafael; HJORLAND, Birger. O conceito de informação. Perspectivas em Ciência da Informação, Minas Gerais, v. 12, n. 1, p. 148-207, Jan./Abr. 2007.

Disponível em:

<http://portaldeperiodicos.eci.ufmg.br/index.php/pci/article/view/54/47>. Acesso em: 14 Ago. 2014.

COSTA, Bianca Mandarino da. Conservação e preservação de fotografias albuminadas. Monografia - Universidade Federal do Estado do Rio de Janeiro. Centro de Ciências Humanas e Sociais. Escola de Museologia. Rio de Janeiro: 2009. Disponível em:

<http://www.bn.br/portal/arquivos/pdf/MONOGRAFIA_Bianca_Mandarino.pdf>. Acesso em: 30 Ago. 2012. 89 p.

CUNHA, Catherine da Silva; PEREZ, Carlos Blaya. Preservação digital de fotografias.

Informação e sociedade: estudos. João Pessoa, v. 24, n. 2, p. 49-55, Maio/Ago. 2014.

Disponível em: <http://www.ies.ufpb.br/ojs2/index.php/ies/article/view/16224/11490>. Acesso em: 21 Nov. 2014.

DELTCI. Dicionário Eletrônico de Terminologia em Ciência da Informação.

Disponivel em: <http://www.ccje.ufes.br/arquivologia/deltci/>. Acesso em: 21 Nov. 2014.

EGGERT-STEINDEL, Gisela et al. Imagens/memórias da Biblioteca Pública de Santa Catarina: uma leitura da memória volátil fixada pela fotografia (1980-2011). 
Perspectivas em Ciência da Informação, v. 18, n. 4. 2013. Disponível em: <http://portaldeperiodicos.eci.ufmg.br/index.php/pci/article/view/1656/1212>. Acesso em: 26 Mar. 2014.

HOUAISS, Antônio. Dicionário Houaiss da Língua Portuguesa. 1. ed. Rio de Janeiro: Objetiva Instituto Antônio Houaiss de Lexicografia, 2009.

KENNEDY, Nora; MUSTARDO, Peter. Preservação de fotografias: métodos básicos para salvaguardar suas coleções. In: Cadernos técnicos de conservação fotográfica (Organização do Centro de Conservação e Preservação Fotográfica da Funarte). Rio de Janeiro: Funarte, 2004, v. 2, p. 17-27. Disponível em:

<http://www.funarte.gov.br/preservacaofotografica/wpcontent/uploads/2010/11/cad2 port.pdf $>$. Acesso em: 11 Out. 2013.

KOSSOY, Boris. Fotografia e história. 2. ed. rev. São Paulo: Ateliê Editorial, 2001. $163 p$.

LE GOFF, J. História e memória. 7. ed. Campinas: Ed. Unicamp, 2013. 499 p.

LEITE, Miriam Lifchitz Moreira. Imagem e memória. Resgate, Campinas, n. 8, p. 916,1998. Disponível em:

<http://www.cmu.unicamp.br/seer/index.php/resgate/article/view/108/113>. Acesso em: 21 Out. 2014.

LUCAS, Clarinda Rodrigues. Leitura e interpretação em biblioteconomia. São Paulo: UNICAMP, 2000. 91 p.

MARCONDES, Marli. Conservação e preservação de coleções fotográficas.

Histórica, São Paulo, v. 1, n. 1, p. 1-13, Abr. 2005. Disponível em:

$<$ http://www.arquivoestado.sp.gov.br/historica/edicoes_anteriores/pdfs/historica01.pd f>. Acesso em: 30 Ago. 2014.

PIMENTA, Ricardo M. O futuro do passado: desafios entre a informação e a memória na sociedade digital. In: ALBAGLI, S. (org.). Fronteiras da Ciência da Informação. Brasília: IBICT, 2013. p. 146-171. Disponível em:

<http://livroaberto.ibict.br/bitstream/1/1020/8/Fronteiras\%20da\%20Ciencia\%20da\%2 Olnform acao.pdf >. Acesso em: 15 Set. 2014.

POZZEBON, Flávia. Manual de Preservação Fotográfica. Rio Grande do Sul: CENTRO DE PESQUISAS GENEALÓGICAS (Nova Palma). 2013. Disponível em: <http://coral.ufsm.br/ppgppc/images/Anexodissertacaopozzebon.pdf>. Acesso em: 11 Out. 2013.

RIBEIRO, Fernanda. O acesso à informação nos arquivos. Lisboa: Fundação Calouste Gulbenkian para a Ciência e a Tecnologia, Ministério da Ciência e do Ensino Superior, 2003. 2v. (Textos universitários de ciências sociais e humanas)

SILVA, Armando Malheiro da. A informação: da compreensão do fenómeno e construção do objecto científico. Porto: Afrontamento, 2006. 176 p. 
SMIT, Johanna W; TÁLAMO, Maria de Fátima Gonçalves Moreira. Sistemas de recuperação de informação e memória. In: ENCONTRO NACIONAL DE PESQUISA EM CIÊNCIA DA INFORMAÇÃO, 7, 2006, São Paulo. Anais eletrônicos. São Paulo: UNESP, 2006. p. 1-11. Disponível em:

<http://www.marilia.unesp.br/sistemas/enancib/viewpaper.php?id=264>. Acesso em: 12 Nov. 2014.

SPINELLI, Jayme. Manual técnico de preservação e conservação. Rio de Janeiro: Fundação Biblioteca Nacional, 2011. 45 p.

TEIXEIRA, Lia Canola. GHIZONI, Vanilde Rohling. Conservação preventiva de acervos. In: Coleção Estudos Museológicos. Vol. 1. Florianópolis: FCC, 2012. Disponível em:

<http://www.fcc.sc.gov.br/patrimoniocultural/arquivosSGC/DOWN_151904Conservac ao_Pre ventiva_1.pdf>. Acesso em: 11 Out. 2013.

TRIGO, Thales. Equipamento fotográfico: teoria e prática. 2. ed. São Paulo: Senac, 1998. 243 p.

Universidade Federal do Rio Grande do Norte. Portal da UFRN. Disponível em: <www.ufrn.br/>. Acesso em: 20 Nov. 2014. 